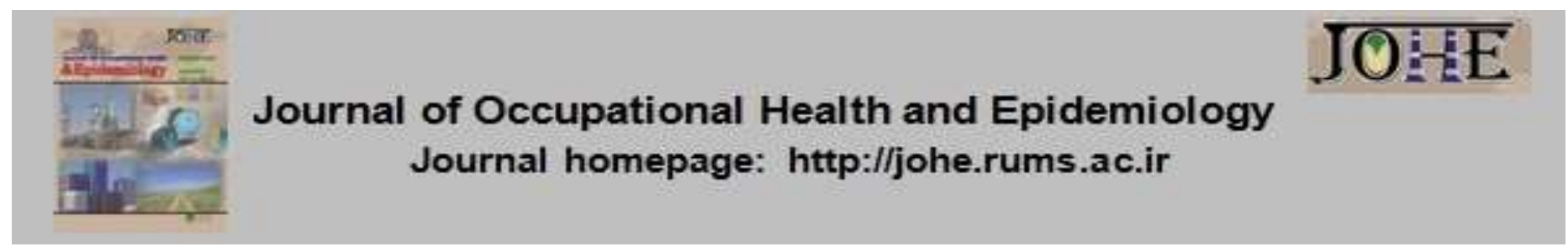

\title{
A survey of the safe use determinants of pesticides in Ardakan pistachio farmers according to the Health Belief Model
}

\author{
Seyed Saeed Mazloomy Mahmoodabad ${ }^{1}$, Mojtaba Fattahi Ardakani2*, Narges Hossein Zadeh ${ }^{3}$, \\ Seyed Mostafa Mazloomy Mahmoodabad ${ }^{4}$, Nooshin Yoshany ${ }^{5}$, Marjane Ghasemine Zhad ${ }^{6}$ \\ 1. Professor, Social Determinants of Health Research Center, School of Public Health, Shahid Sadoughi University of Medical \\ Sciences, Yazd, Iran. \\ 2. PhD of Health Education and Health Promotion, School of Public Health, Shahid Sadoughi University of Medical Sciences, Yazd, \\ Iran. \\ 3. MSc of Health Education, School of Public Health, Shahid Sadoughi University of Medical Sciences, Yazd, Iran. \\ 4. Bachelor of Primary Education, Yazd, Iran. \\ 5. PhD Student of Health Education and Promotion, Social Determinants of Health Research Center, School of Public Health, Shahid \\ Sadoughi University of Medical Science, Yazd, Iran. \\ 6. MSc of Health Education, School of Public Health, Shahid Sadoughi University of Medical Science, Yazd, Iran.
}

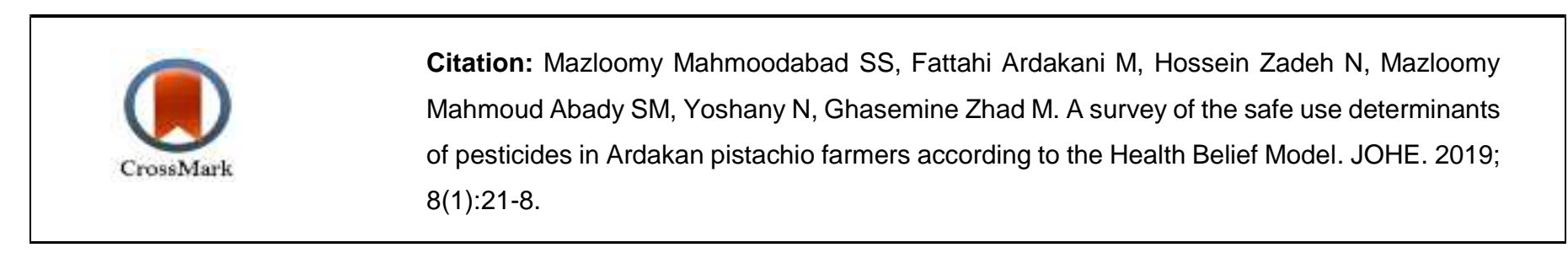

\section{Article Info}

${ }^{*}$ Corresponding author: Mojtaba Fattahi Ardakani, E-mail:

mjfattagi57@gmail.com

\section{Article history}

Received: Sep, 2018

Accepted: Jan, 2019

10.29252/johe.8.1.21

\section{Print ISSN: 2251-8096} Online ISSN: 2252-0902

Peer review under responsibility of Journal of Occupational Health and Epidemiology

\section{Abstract}

Background: To eliminate the pests of their crops and gardens, farmers use pesticides, where the unsafe use and lack of knowledge of using them inflict irreparable physical harms to them and those around them. Therefore, this study was done to find out which behaviors are the determinants of the safe use of pesticides among pistachio farmers in Ardakan city based on the Health Belief Model.

Materials and Methods: This cross-sectional study, with a descriptive correlational approach, was conducted in 2014 on 301 farmers selected via proportionate stratified random sampling using a researcher-made questionnaire in Ardakan city. The questionnaire consisted of demographic variables and HBM constructs, such as perceived susceptibility, perceived severity, perceived benefits, perceived barriers, self-efficacy, cues to action, and safety behaviors.

Results: The mean score of knowledge was $25.64 \pm 7.45$ out of 38 , and the subjects received $60 \%$ of the score. In addition, the mean score of perceived susceptibility was $32.72 \pm 7.79$ out of 55 , the mean score of perceived severity was $33.53 \pm 8.44$ out of 55 , the mean score of perceived benefits was $25.99 \pm 5.59$ out of 30 , and the mean score of perceived barriers was $17.99 \pm 4.5$ out of 30 . Other results are presented in the section 'results' of the article.

Conclusions: Given the mean scores obtained, there is a need for developing a training program based on the results to reduce damage caused by pesticides, with safe measures to be adopted.

Keywords: Pesticides, Occupational Health, Farmers

\section{Introduction}

Since the Green Revolution until now, the use of pesticides has played a crucial role in food production (1). At the present time, the use of pesticides has turned into an inseparable part of modern agriculture (2). About 2.9 million tons of pesticides are annually used in the world, with $85 \%$ of which used by the agricultural sector. Despite this statistic, the use of pesticides is on the rise in the world (3). Nowadays, half of the global workforce (about 1.4 billion people) work in the agricultural sector with $65 \%$ of which suffering from the adverse effects of pesticides (4). Due to the positive attitude of farmers towards the use of pesticides and the high use of them, more attention is being paid to their adverse effects at the time of mixing and spraying them, working at farms polluted by 
pesticides, pesticides left on products, and drinking water (5). The misuse of pesticides can exert harmful effects on human health (6), with some symptoms appearing in acute and chronic forms. Acute symptoms include nausea, vomiting, headache, stomachache, and a change in the heart rhythm that appear from a few minutes to a few hours after exposure to pesticides. In addition, long exposure to pesticides causes weakness, dizziness, chest pain, and unconsciousness (7).

Researchers have demonstrated that pesticides can cause cancer, reproduction system diseases, damage to kidneys, liver and lungs, neurological problems (8), immune system disorders, hormonal disorders, intellectual power reduction (9), and circulatory system disorders (7) in human beings. The World Health Organization announced that $3,000,000$ cases of poisoning and 220,000 deaths happen annually throughout the world due to the use of pesticides, while the lack of protection and inappropriate use of pesticides increase the chances of being exposed to them and their resulting adverse effects (8). The risk of occupational diseases caused by exposure to pesticides is high among farmers due to insufficient trainings (10). The lack of knowledge of the safe use of pesticides, poor spraying techniques, and not using personal protective equipment (PPE) while using pesticides play an important role in causing diseases (11). Numerous studies have implied the necessity of training programs for farmers for the safe use of pesticides $(11,12)$. The rate of using pesticides in the agricultural sector in Iran reaches $26,000,000$ liters per year (13). The pistachio cultivation area in Ardakan city is 7500 hectares, with $8.3 \%$ of its people (about 2,170 people) working in the agricultural sector (14).

Studies on the present subject imply that Iranian farmers either have insufficient information about the method of protecting themselves against harmful agents at the workplace or are not committed to adopting protective measures (15). According to the studies carried out on farmers in 5 cities of Iran, only $25 \%$ of them were aware of the harms of pesticides (16). Numerous studies imply the need for appropriate training planning for farmers $(4,15,17$, and 18). The Health Belief Model (HBM) is one of the early theories developed about health behaviors. This theory was proposed in the 1950s. The HBM includes the six constructs of perceived sensitivity, perceived intensity, perceived benefits, perceived barriers, cues to action, and self-efficacy, studied under various conditions (20). The study on Thai farmers aimed at studying health beliefs about the safe use of pesticides implied that the scores of the constructs of the model were moderate (21). According to this introduction, the present study was conducted to identify the behaviors which are the determinants of the safe use of pesticides among pistachio farmers in Ardakan City, based on the Health Belief Model.

\section{Materials and Methods}

To collect data, a combination of library and field research methods was used in the present research paper. The library method was used to collect information on the theoretical basics and research literature, with books, internet paper sources, and similar studies taken into account for this purpose. This descriptive study was conducted using a crosssectional analysis. Considering the confidence level of $\% 95, P=\% 50$, and the estimation error of $\% 6,270$ subjects were included in the study; however, to assure the reliability of the results, 301 farmers of Ardakan city located at the center of Iran were included from the three pistachio regions of AhmadAbad, Hassan Abad Anaraki, and Chah Afzal. The farmers were selected from the villages where pistachios were the main agricultural product. The three mentioned regions were selected for sampling the households, with a list produced containing the members of these households working on the farms. The inclusion criteria for the farmers were having at least 3 years of work experience with pesticides in greenhouses, and living in Ardakan city where they were working. Farmers who had not ever sprayed pesticides and were not living in Ardakan city were excluded from the study. In case more than one person in a household was working on the farm, one of them would be selected randomly. Next, 301 subjects were selected randomly from the list of the farmers. The following step was to coordinate with the selected farmers and have the researcher-made questionnaire filled out by trained people by meeting them at the door of their houses. The collected data were analyzed using SPSS Statistics Version 19. Descriptive statistics, the table of frequency, and the Pearson correlation coefficient were used to analyze the data.

The reliability (Cronbach's Alpha $=0.80$ ) and validity of the questionnaire were approved in past research (20). The questionnaire consisted of four parts, with the first part consisted of five questions about demographic variables, and the second part composed of 19 questions.

The third part of the questionnaire was related to HBM constructs, including perceived sensitivity (11 items), perceived threats (11 items), perceived benefits ( 6 items), perceived barriers $(6$ items), self-efficacy (5 items), and cues to action (8 items). The fourth part of the questionnaire was 
about behaviors (19 items). The five-point Likert scale was used to answer the questions.

To examine the data, a field study was conducted in the present research paper. The field study included interviews and questionnaires aimed at obtaining information on accepting or rejecting the research hypothesis.

The objectives of this study were explained to the farmers. In addition, they were assured of the confidentiality of their information, with written informed consent obtained from them. In addition, the present research was approved by the research committee of Shahid Sadoughi University of Medical Sciences under code 2962 on 18/05/2013.

\section{Results}

In the present research, 301 male participants included 159 individuals (52.8\%) from Ahmad Abad village, 116 individuals (38.5\%) from Chah Afzaland village, and 26 individuals (8.6\%) form Hassan Abad Anaraki village. The mean age of the farmers was $44.8 \pm 13.6$ years, the mean work experience of theirs was $20.8 \pm 12.8$ years, the highest work experience was 68 years, and the lowest work experience was a few months.
Regarding the farmers' levels of education, 40 subjects (13.6\%) could read and write, 56 subjects (19\%) had completed primary education, 63 subjects $(21.4 \%)$ had finished the 3rd grade of their middle-school, 80 subjects $(26.6 \%)$ had a high school diploma, and 56 of them (18.6\%) had an associate degree or a higher degree.

A total of 285 subjects (94.7\%) used motor vehicles to spray pesticides, and 8 subjects (2.7\%) performed it manually. From among 216 subjects who answered the question of 'What kind of poison do you use?', 95 individuals (44\%) stated that they used Fozalone, 116 individuals (55.5\%) said they used Amitraz, and $26.2 \%$ of them stated that they were poisoned by pesticides.

Table 1 shows that about $80.4 \%$ of the farmers regarded the eye as one way to transport poison to the body, and $95 \%$ of them were affected through their mouth. In addition, $27.6 \%$ of them regarded tinnitus, $48 \%$ considered fidget, and $42.5 \%$ of them considered sweating as the signs of poisoning. Likewise, $90 \%$ of them considered dizziness as the sign of poisoning. Furthermore, $55.1 \%, 88.7 \%$, and $65.4 \%$ of the subjects considered stomachache, nausea and vomiting, as well as weakness and lethargy as the signs of poisoning, respectively.

Table 1: The frequency distribution of the answers to the questions about the subjects' awareness in the three villages

\begin{tabular}{|c|c|c|c|c|c|c|}
\hline \multicolumn{2}{|c|}{ Questions about subjects' awareness } & \multicolumn{3}{|c|}{ Right } & \multicolumn{2}{|c|}{ Wrong } \\
\hline \multirow{4}{*}{$\begin{array}{l}\text { Awareness of the } \\
\text { way poisons enter } \\
\text { the body }\end{array}$} & \multirow{4}{*}{$\begin{array}{l}\text { Which one of these } \\
\text { items is the way } \\
\text { through which } \\
\text { poisons enter the } \\
\text { body? }\end{array}$} & & Number & Percent & Number & Percent \\
\hline & & Skin & 225 & 74.8 & 76 & 25.2 \\
\hline & & Eyes & 242 & 80.4 & 58 & 19.3 \\
\hline & & Breathing & 283 & 64 & 18 & 6 \\
\hline & \multirow{12}{*}{$\begin{array}{c}\text { Which one of these } \\
\text { items is the sign of } \\
\text { poisoning? }\end{array}$} & Mouth & 285 & 95 & 15 & 5 \\
\hline \multirow{11}{*}{$\begin{array}{c}\text { Awareness of } \\
\text { poisoning symptoms }\end{array}$} & & Eye irritation & 242 & 80.4 & 61 & 19.6 \\
\hline & & $\begin{array}{l}\text { High level of } \\
\text { sweating }\end{array}$ & 128 & 42.5 & 173 & 57.5 \\
\hline & & Chest pain & 188 & 62.5 & 103 & 37.5 \\
\hline & & Tinnitus & 83 & 27.6 & 218 & 72.5 \\
\hline & & Feeling weak & 197 & 65.4 & 104 & 34.5 \\
\hline & & Blurred vision & 185 & 61.5 & 117 & 38.6 \\
\hline & & Fidget & 148 & 48.7 & 154 & 51.3 \\
\hline & & Stomachache & 166 & 55.1 & 135 & 44.9 \\
\hline & & Diarrhea & 206 & 68.4 & 95 & 31.5 \\
\hline & & Dizziness & 269 & 89.4 & 34 & 10.6 \\
\hline & & $\begin{array}{l}\text { Nausea and } \\
\text { vomiting }\end{array}$ & 267 & 88.7 & 34 & 10.3 \\
\hline
\end{tabular}

The results of Table 2 show that the mean awareness score of the participants was $25.64 \pm$ 7.45 out of 38 , so they obtained $60 \%$ of the score. In addition, the mean score of perceived sensitivity was $32.72 \pm 7.79$ out of 55 , so they obtained a moderate score. The mean score of perceived intensity was $33.53 \pm 8.44$ out of 55 , and the mean score of perceived benefits was $25.99 \pm 5.59$ out of 30. Likewise, the mean score of perceived barriers was $17.99 \pm 4.5$ out of 30 , and the mean score of perceived self-efficacy was $17.99 \pm 4.5$ out of 25 . In addition, the mean scores of clues to action and preventive behaviors were $2.62 \pm 1.62$ out of 8 and $45.15 \pm 8.15$ out of 57 , respectively. 
Table 2: The general mean scores of the constructs of the Health Belief Model in the three villages

\begin{tabular}{lcccc}
\hline \multicolumn{1}{c}{ Variable } & General mean & $\begin{array}{c}\text { Standard } \\
\text { deviation }\end{array}$ & $\begin{array}{c}\text { Maximum-minimum } \\
\text { scores }\end{array}$ & Total percentage \\
\hline Awareness & 25.69 & 7.45 & $4-38$ & 65 \\
\hline Perceived sensitivity & 32.72 & 7.79 & $11-55$ & 58 \\
\hline Perceived intensity & 33.53 & 8.44 & $18-55$ & 60 \\
\hline Perceived benefits & 25.99 & 5.59 & 3.90 & 86.66 \\
\hline Perceived barriers & 17.99 & 4.5 & $5-25$ & 72 \\
\hline Perceived self-efficacy & 17.99 & 4.5 & $5-25$ & 72 \\
\hline Clues to action & 2.62 & 1.62 & $0-8$ & 32.75 \\
\hline Preventive behaviors & 45.15 & 8.15 & $19-57$ & 79 \\
\hline
\end{tabular}

Table 3 shows that $41 \%$ of the farmers always used gloves, and $59 \%$ of them did not use glasses when spraying pesticides. In addition, $45 \%$ of the farmers used front-covered shoes while spraying pesticides. Besides, $43 \%$ of them did not ever use protective masks when spraying pesticides, and $55 \%$ of them read the information on the container's label before spraying pesticides. Furthermore, $43 \%$ of them disposed of empty poison containers according to the label. In addition, $72 \%$ of the farmers always washed their hands after spraying pesticides, and $54.5 \%$ of them always used label information to mix poisons.

Table 3: The frequency distribution of the preventive behaviors of the farmers exposed to pesticides

\begin{tabular}{|c|c|c|c|c|c|c|c|c|}
\hline \multirow{2}{*}{\multicolumn{3}{|c|}{$\begin{array}{l}\text { Questions about preventive behaviors when faced } \\
\text { with pesticides }\end{array}$}} & \multicolumn{2}{|c|}{ Never } & \multicolumn{2}{|c|}{ Sometimes } & \multicolumn{2}{|c|}{ Always } \\
\hline & & & $\frac{\grave{d}}{\text { है }}$ & 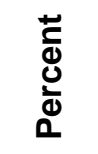 & 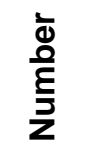 & 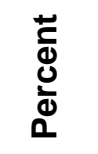 & $\begin{array}{l}\frac{1}{d} \\
\frac{\varrho}{E} \\
\frac{\Sigma}{Z}\end{array}$ & 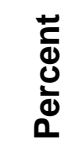 \\
\hline \multirow{6}{*}{$\begin{array}{l}\text { Using personal } \\
\text { protective } \\
\text { equipment }\end{array}$} & \multirow{6}{*}{$\begin{array}{l}\text { Which type of } \\
\text { equipment do } \\
\text { you use while } \\
\text { spraying } \\
\text { pesticides? }\end{array}$} & Gloves & 84 & 27.9 & 91 & 30.2 & 126 & 41.9 \\
\hline & & $\begin{array}{l}\text { Boots or front- } \\
\text { covered shoes }\end{array}$ & 75 & 24.9 & 90 & 29.9 & 136 & 45.2 \\
\hline & & Special uniforms & 80 & 26.6 & 81 & 26.9 & 146 & 45.2 \\
\hline & & Masks & 53 & 17.6 & 118 & 39.2 & 130 & 43.2 \\
\hline & & Protective glasses & 176 & 58.5 & 78 & 25.9 & 47 & $\overline{15.6}$ \\
\hline & & Helmets & 108 & 35.9 & 103 & 34.2 & 90 & 29.9 \\
\hline \multicolumn{3}{|c|}{ I read the container's label before spraying pesticides. } & 35 & 11.6 & 99 & 32.9 & 167 & 55.5 \\
\hline \multicolumn{3}{|c|}{$\begin{array}{l}\text { I read the container's label and use the recommended } \\
\text { amount of poisons before mixing them. }\end{array}$} & 29 & 9.6 & 108 & 35.9 & 164 & 54.5 \\
\hline \multicolumn{3}{|c|}{$\begin{array}{l}\text { I act according to the container's label to dispose of } \\
\text { the empty containers of poisons. }\end{array}$} & 66 & 21.9 & 132 & 43.9 & 103 & 34.2 \\
\hline \multicolumn{3}{|c|}{$\begin{array}{l}\text { I wash my hands with soap and water before eating } \\
\text { and drinking. }\end{array}$} & 15 & 5 & 67 & 22.3 & 219 & 72.7 \\
\hline
\end{tabular}

According to Table 4, with an increase in age, the subjects' awareness decreases, indicating a negative correlation between awareness and age. The more the work experience is, the more the awareness of the appropriate signs and measures will be. In addition, with an increase in the level of education, the mean scores of awareness, perceived sensitivity, perceived intensity, perceived benefits, perceived barriers, perceived self-efficacy, and preventive behaviors will increase.

In addition, with an increase in work experience, the mean score of perceived benefits will decrease, being indicative of a negative correlation between work experience and perceived benefits.

Table 4: Pearson correlation coefficients for demographic variables (age and work experience) and the parameters examined for research subjects

\begin{tabular}{ccccccccc}
\hline & Awareness & $\begin{array}{c}\text { Perceived } \\
\text { sensitivity }\end{array}$ & $\begin{array}{c}\text { Perceived } \\
\text { intensity }\end{array}$ & $\begin{array}{c}\text { Perceived } \\
\text { benefits }\end{array}$ & $\begin{array}{c}\text { Perceived } \\
\text { barriers }\end{array}$ & $\begin{array}{c}\text { Perceived } \\
\text { self-efficacy }\end{array}$ & $\begin{array}{c}\text { Clues to } \\
\text { action }\end{array}$ & $\begin{array}{c}\text { Preventive } \\
\text { behaviors }\end{array}$ \\
\hline Age & $-0.250^{* *}$ & -0.110 & -0.035 & -0.005 & -0.065 & -0.100 & 0.035 & -0.068 \\
\hline $\begin{array}{c}\text { Work } \\
\text { experience }\end{array}$ & $-0.209^{* *}$ & -0.012 & 0.019 & $-0.116^{*}$ & 0.083 & -0.082 & 0.047 & 0.045 \\
\hline $\begin{array}{c}\text { Level of } \\
\text { education }\end{array}$ & $0.313^{* *}$ & $0.218^{* *}$ & $0.147^{*}$ & $0.156^{* *}$ & -0.108 & $0.127^{*}$ & 0.045 & $0.122^{*}$ \\
\hline
\end{tabular}


* Significant at the level of 0.01

${ }^{*}$ * Significant at the level of 0.05

\section{Discussion}

This study was carried out in order to investigate the level of awareness of farmers and their risk preventive behaviors in dealing with pesticides, based on the Health Belief Model. According to the results, $60 \%$ of the farmers were aware of the ways poisons entered their body and recognized the symptoms of poisoning, and the ways of dealing with it. The level of awareness of the present subjects was higher than that of the people of Amin Shahr Village. In the same vein, the level of awareness of the farmers in this study was higher than that of the farmers in the study of Aghilinejad et al (16) and that of the farmers in Qom City in the study of Heydari and Razavi (4). Furthermore, the mean score of awareness of the farmers in this study was consistent with the level of awareness of farmers in a study in Southern Khorasan, which showed that $57.3 \%$ of them were moderately aware of occupational health (16). In the study in Gaza by Yasin et al on the level of awareness of poisoning symptoms and the ways through which poisons enter the body, it was concluded that the level of awareness of the farmers was moderate, having been in line with the results of the current study (21). In the study by Watchman on the awareness of farmers and the use of the labels on poison containers by them, the farmers were not aware enough, with this result being consistent with the results of the present study (19).

In the present study, $80 \%$ of research participants recognized eyes as the way through which poisons enter the body, which was consistent with the results of the study of Yasin and et al (21). In this study, the variable of awareness was negatively correlated with age and work experience so that with an increase in age, the level of awareness decreased. In contrast, the variable of awareness was positively correlated with the level of education, which was also in line with the study of Hosseini et al (15). These results indicate that an increase in the level of awareness is the key to reducing the rate of diseases caused by pesticides, which can be accompanied by secure behaviors.

The mean scores of the perceived sensitivity and perceived severity of the farmers were not high. According to the Health Belief Model, people feel threatened with the lack of safe and proper behaviors. Therefore, they need to be informed about the results of the lack of safe behaviors (22). This result was consistent with the results of the study of Arcury in which about $20-30 \%$ of farmers did not have enough awareness of poisons, and about $22 \%$ of them were not sensitive to their health in connection with poisons (23). This study is also consistent with the study on Thai rice farmers (20) in which perceived sensitivity and intensity had a significant correlation with the level of awareness. In some studies, with an increase in the level of awareness, the perceived risk decreased (23), and in some other cases, with an increase in the level of awareness, the perceived risk increased as well (24, 20, and 22).

In the present study, the mean score of perceived benefits was high. In contrast, the mean score of perceived barriers in farmers was low. This result was consistent with the study carried out on Indonesian farmers (25). However, it was higher in the study of Raksanaman (26) in which perceived benefits and barriers were moderate, with this being due to the type and platform of the study (20). In the aforementioned study, perceived benefits had no significant correlation with the independent variables of age and level of education, but there was a negative correlation between perceived benefits and work experience at the level of 0.05 ; in other words, with an increase in the work experience, the mean score of perceived benefits in farmers concerning secure behaviors when exposed to pesticides decreased. According to the results of Devi's research in India (12), highly experienced farmers believed that the use of pesticides for a long time had no adverse effects on them. They also believed that they were immune to the adverse effects of pesticides. Therefore, they did not consider preventive behaviors necessary. In the study of Asghari, a significant correlation was observed between the level of education and perceived benefits, being consistent with the present study. Given the fact that with an increase in work experience the level of education decreases among farmers, being established in this study as well, it can be concluded that people with higher levels of education are more aware of the adverse effects of pesticides. Therefore, they have more perceived benefits from preventive and secure behaviors. Research results of the study of VAughan showed that considering the high level of perceived benefits in the study group, self-care behaviors had a significant negative correlation with the increase in the work experience (27).

Based on the research results, the major perceived barriers among farmers to preventive behaviors when exposed to pesticides were the lack of understanding of the instructions of the poison container's label (48.2 percent) and their unawareness of self-care methods. According to the results obtained, the lack of awareness of the 
instructions on the poison container's label leads to a reduction in workers' performance in using pesticides securely. In addition, there was no correlation between perceived barriers and the demographic variables of age, work experience, and level of education. These findings imply that no appropriate interventional planning has been done to improve farmers' knowledge and skills of health behaviors. According to the results of the study of Singh and Gupta (28), the low levels of awareness and the lack of knowledge of the safe use of pesticides are the major factors in decreasing farmers' performance, which in turn make them become exposed to the adverse effects of pesticides. In the present study, the mean score of perceived self-efficacy was moderate. This result was in line with the study by Arcury et al in which farmers felt strong enough to prevent the adverse effects of pesticides. Work experience had no correlation with the control of perceived behaviors, being in line with the study of Arcury et al (23). In this study, perceived self-efficacy had a significant positive correlation with the level of awareness and education; in other words, with an increase in the level of awareness and skills, farmers can protect themselves against the harms of pesticides, with a higher level of self-efficacy in secure behaviors obtained. This means that people with higher levels of education will better understand instructions on the pesticide container's label, with their knowledge being more of the methods of using pesticides.

In the present study, the mean score of clues to action was low and formed only $32 \%$ of the maximum score, having been the lowest score among the scores of all other constructs. This indicates that people, organizations, and mass media have not played a significant role in informing farmers about the use of pesticides. In this study, it was realized that farmers had gained the major part of the information about using pesticides from their family $(60.5 \%)$, other farmers $(58 \%)$, and health centers (42\%); however, only $26.6 \%$ of the farmers had gained their knowledge of the use of pesticides by radio, and $34.6 \%$ of them had gained it on television. According to the research results, there was no significant correlation between the construct of clues to action and the demographic variables of age, work experience, and the level of education. The findings indicate that proper planning has not been done to encourage farmers in adopting health behaviors.

The results of this study showed that there was a moderate score of safe behaviors in farmers in using pesticides. In addition, the results showed that $41 \%$ of the farmers always used gloves, $59 \%$ of them never used glasses, and $45 \%$ of them used front-covered shoes while spraying pesticides. More results showed that $43 \%$ of the farmers never used respiratory protective masks, $55 \%$ of them read the information on the container's label before spraying pesticides, and $43 \%$ of them sometimes disposed of containers according to the information printed on the container's label. Studies show that the use of self-care tools decreases skin exposure to poisons (27).

The results presented above are consistent with the study of Menken and Agonafir (29). They are also in line with the study of Strong et al (30) in which $80 \%$ of the farmers washed their hands after spraying pesticides, and $42 \%$ of them used boots. However, the important point is that not using glasses, masks, front-covered shoes, and the incorrect disposal of poison containers in $40 \%$ of the farmers indicate their insufficient knowledge of the importance of poisoning by pesticides and the environment. According to the results of the study done by Zhang et al, the probability of pesticide poisoning is significantly correlated with the risky behaviors of exposure to pesticides (31).

The study of Salvatore et al showed that exhibiting the behaviors suggested by the Worker Protection Standard (WPS), like wearing long sleeve shirts, pants, gloves, and a helmet, as well as washing hands, changing contaminated clothes, and taking a bath right after spraying pesticides play a crucial role in decreasing exposure to pesticides (32).

The research results showed that from among demographic variables, the level of education was positively correlated with preventive behaviors, being consistent with some other studies (8 and 11). Given the aforementioned facts as well as the mass media not informing farmers about the importance of secure behaviors before and after spraying pesticides and relevant adverse effects, appropriate measures must be adopted and thoughtful planning should be done. Considering the variety of agricultural products in the country and that each product has a limited spraying season, constructing a season-based training model can change farmers' self-protective behaviors in the short run. The filling out of the questionnaire in a self-report manner was one of the limitations of the present study, which was based on the recollection of the farmers.

\section{Conclusion}

There is no training program aimed at improving the farmers' level of awareness in protecting themselves against the harmful effects of pesticides. The lack of training programs is the reason for the low awareness of the farmers in protecting themselves while spraying pesticides. Thus, this lack of knowledge has led to their improper attitude towards safety behaviors. 


\section{Acknowledgement}

This paper was extracted from a research project with the number 6291 (19/12/2013) and was approved by the Research Council of the School of Public Health at Shahid Sadoughi University of Medical Sciences and Health Services in Yazd City, which was financially supported by the Research Department. The authors would like to express their sincere gratitude to everybody who assisted them in producing this paper.

Conflict of interest: None declared.

\section{References}

1. Amoguis DMK, Bontilao ShMR, Galarido ChD, Lumamba JAW, Paelmo JNA, Rosal RMB. Experiences in pesticide used among farm workers and its effect to their health. Advancing Nursing Research 2012; 2(1):28-39.

2. Oluwole O, Cheke RA. Health and environmental impacts of pesticide use practices: a case study of farmers in Ekiti State, Nigeria. Int J Agric Sustain 2009; 7(3):153-63.

3. Atreya K, Sitaula BK, Bajracharya RM. Pesticide use in agriculture: The philosophy, complexities and opportunities. Scientific Research and Essays 2012;7(25):2168-73

4. Mazloomi Mahmoodabad SS, Rezaeian M, Hosseinzadeh N, Fallahzadeh H, Barkhordari A. Effectiveness of education based on Health Belief Model (HBM) on preventive behaviors of pesticide exposure in agricultural worker. Tolooe-Behdasht 2016; 14(6):247-60.

5. Damalas CA, Eleftherohorinos IG. Pesticide exposure, safety issues, and risk assessment indicators. Int J Environ Res Public Health 2011; 8(5):1402-19.

6. Ajayi OC, Akinnifesi FK. Farmers' understanding of pesticide safety labels and field spraying practices: a case study of cotton farmers in northern Côte d'Ivoire. Scientific Research and Essays 2007; 2(6):204-10.

7. Lucas SF, Allen P. Reducing the risk of pesticide exposure among children of agricultural workers: How nurse practitioners can address pesticide safety in the primary care setting. Pediatr Nurs 2009; 35(5):308-17.

8. Razzaghi A, Khanjani N, Daneshi S. Contamination with organophosphate toxins in humans in Iran: A systematic review. Health and Development Journal 2016; 5(1):90-7.

9. Shrestha P, Koirala P, Tamrakar AS. Knowledge, practice and use of pesticides among commercial vegetable growers of Dhading district, Nepal. Journal of Agriculture and Environment 2010; 11:95-100.

10. Magauzi R, Mabaera $B$, Rusakaniko $S$, Chimusoro A, Ndlovu N, Tshimanga $M$, et al. Health effects of agrochemicals among farm workers in commercial farms of Kwekwe district, Zimbabwe. Pan Afr Med J 2011; 9(1):206.

11. Hashemi SM, Hosseini SM, Hashemi MK. Farmers' perceptions of safe use of pesticides: determinants and training needs. Int Arch Occup Environ Health 2012; 85(1):57-66.
12. Devi PI. Health risk perceptions, awareness and handling behaviour of pesticides by farm workers. Agricultural Economics Research Review 2009; 22:263-8.

13. Dehghani R, Limoee M, Zarghi I. The review of pesticide hazards with emphasis on insecticide resistance in arthropods of health risk importance. Scientific Journal of Kurdistan University of Medical Sciences 2012; 17(1):8298.

14. Marzban A, Sheikdavoodi MJ, Almassi M, Bahrami H, Abdeshadi A, Shishebor P. Pesticide application poisoning incident among Iranian rice growers and factors influence it. International Research Journal of Applied and Basic Sciences 2012; 3(2):378-82.

15. Eslami H, Almodaresi SA, Khosravi R, Fallahzadeh RA, Peirovi $R$, Taghavi $M$. Assessment of groundwater quality in YazdArdakan plain for agricultural purposes using Geographic Information System (GIS). Journal of Health 2018; 8(5):575-86.

16. Hosseini $M H$, Ramazani A, Hanafie Bojd M, Hamidi $\mathrm{H}$, Samimi K, Mohsenzadeh MA, et al. Farmers' knowledge of occupational poisonings in South Khorasan, 2009. Journal of Birjand University of Medical Sciences 2011; 18(1):4754.

17. Aghilinejad MA, Mohamadi S, Farshad AA Effect of pesticides on farmers' health. Journal of Research in Medical Sciences 2008; 31(4):32731.

18. Hashemi SM, Rostami R, Hashemi MK, Damalas ChA. Pesticide use and risk perceptions among farmers in southwest Iran. Human and Ecological Risk Assessment: An International Journal 2012; 18(2): 456-70.

19. Marzban A, Sheikdavoodi MJ, Almassi M, Bahrami H, Abdeshahi A, Shishebor P. Pesticide application poisoning incident among Iranian rice growers and factors influence it. International Research Journal of Applied and Basic Sciences 2012; 3(2):378-82.

20. Shojaeizadeh D, Heydarnia A,Ghofranipour F, Pakpour Hajiagha A, Saffari M. Health education \& promotion: Theories, models \& methods. 1st ed. Tehran: Sobhan; 2009.

21. MazloomiMahmoodabad SS, Rezaeian M, Hosseinzadeh N, Fallahzadeh H, Barkhordari A. Effectiveness of education based on Health Belief Model (HBM) on preventive behaviors of pesticide exposure in agricultural worker. The Journal of Toloo-e-Behdasht 2016; 14(6):247-60

22. Yassin MM, Abu Mourad TA, Safi JM. Knowledge, attitude, practice, and toxicity symptoms associated with pesticide use among farm workers in the Gaza Strip. Occup Environ Med 2002; 59(6):387-93.

23. Waichman AV, Eve E, da Silva Nina NC. Do farmers understand the information displayed on pesticide product labels? A key question to reduce pesticides exposure and risk of poisoning in the Brazilian Amazon. Crop Prot 2007; 26(4):576-83.

24. Arcury TA, Quandt SA, Russell GB. Pesticide safety among farmworkers: perceived risk and perceived control as factors reflecting environmental justice. Environ Health Perspect 2002; 110(Suppl 2):233-40.

25. Martinez R, Gratton TB, Coggin C, Rene A, Waller W. A study of pesticide safety and health perceptions among pesticide applicators in 
Tarrant County, Texas. J Environ Health 2004; 66(6):34-7.

26. Suratman S, Ross K, Babina K, Edwards JW. The effectiveness of an educational intervention to improve knowledge and perceptions for reducing organophosphate pesticides exposure among Indonesian and South Australian migrant farmworkers. Risk Manag Healthc Policy 2016; 9:1-12.

27. Raksanam B, Taneepanichskul S, Robson MG, Siriwong W. Health risk behaviors associated with agrochemical exposure among rice farmers in a rural community, Thailand: a communitybased ethnography. Asia Pac J Public Health 2014; 26(6):588-95.

28. VAughan E. Chronic exposure to an environmental hazard: risk perceptions and selfprotective behavior. Health Psychol 1993; 12(1):74-85

29. Singh B, Gupta MK. Pattern of use of personal protective equipment's and measures during application of pesticides by agricultural workers in a rural area of Ahmednagar district India. Indian J Occup Environ Med 2009; 13(3):127-34.

30. Mekonnen Y, Agonafir T. Pesticide sprayers' knowledge, attitude and practice of pesticide use on agricultural farms of Ethiopia.Occup Med (Lond) 2002; 52(6):311-5.

31. Strong LL, Starks HE, Meischke H, Thompson B. Perspectives of mothers in farmworker households on reducing the take-home pathway of pesticide exposure. Health Educ Behav 2009; 36(5):915-29.

32. Zhang X, Zhao W, Jing R, Wheeler K, Smith GA, Stallones $L$, et al. Work-related pesticide poisoning among farmers in two villages of Southern China: a cross-sectional survey. BMC Public Health 2011;11:429.

33. Salvatore AL, Bradman A, Castorina R, Camacho J, López J, Barr DB, et al. Occupational behaviors and farmworkers' pesticide exposure: findings from a study in Monterey County, California. Am J Ind Med 2008; 51(10):782-94. 